\title{
The Urgent Need to Increase Palliative Care Services for Children with Cancer in the United States
}

\author{
Robert W Buckingham* and Renata Ferretti \\ University of Michigan in Flint Michigan, Ann Arbor, Michigan, USA \\ *Corresponding Author: Robert W Buckingham, University of Michigan in Flint \\ Michigan, Ann Arbor, Michigan, USA.
}

Received: November 06, 2020

Published: December 08, 2020

(C) All rights are reserved by Robert W

Buckingham and Renata Ferretti.

\begin{abstract}
Background: The discovery of a fatal disease marks the beginning of the child dying trajectory. However, the lack of availability of palliative care services for children with cancer is a challenge for families in the United States.

Aim: This study is two-fold. The first is to identify the demand for palliative care services for children with cancer. The second is to determine the precise and geographical availability of palliative care services for children in the end-stage disease in the United States.

Design: This study is secondary research.

Data Sources: The research's base is data from organizations as the CDC and NHPCO. The criteria for selecting other studies has focused on research with a confirmed data source that addresses pediatric palliative care services and challenges facing by children with cancer between 1996 to 2020.

Results: In 2016, in the United States, 2118 children aged less than 19 years died from cancer and of this total, 37\% died at parent>s homes. It appears that the majority of these children were not supported by palliative care service, given that only $3.48 \%$ of palliative care services clearly stated that they have a pediatric program, out of a total of 2,330 listed on the NHPCO website.

Conclusion: The number of palliative care services for children should be increased in the United States. Adultıs palliative care services could consider training their staff to address the needs of children and families. Governmental Agencies could encourage further research to develop more pediatric programs and services for children who are facing a terminal illness.
\end{abstract}

Keywords: Child; Neoplasms; Palliative Care; Terminal Care; Home Care Services

\section{Background}

Children with life-limiting illnesses are approximately 500,00 in the United States each year; although, only $10 \%$ of these children are supported by palliative care services [1,2]. The beginning of the dying trajectory is the discovery of fatal disease, when the child and the family start to live with the ambiguities of an uncertain future [3]. At this moment, it is crucial to retain as possible their daily lives as many aspects of their previous lives, which includes receiving home care.

The terminally ill child requires more affection and love and when the child is at the hospital, probably, this need is not fully achieved. At home, the dying children connected with their loved ones, which gives them a sense of belonging [4]. Palliative care service helps children confront death more sensibly, enables the children to spend more productively the time they have left [3] and enhances the child's quality of life until the end [5]. However, there are many uncertainties about the number of pediatric palliative care services and the number of children enrolled in palliative care services in the United States.

Based on data from federal agency as the Centers for Disease Control and Prevention (CDC) and nonprofit organizations as the National Hospice and Palliative Care Organization (NHPCO), this 
study is two-fold. The first is to identify the demand for palliative care services for children with cancer. The second is to determine the precise and geographical availability of palliative care services for children in the end-stage disease in the United States. Therefore, we intended to answer the following research question: Are there enough palliative care services available for children with a terminal illness in the United States?

\section{Literature Review}

\section{Palliative care for children}

The discovery of a fatal disease marks the beginning of the dying trajectory. After this point, both the child and the family must live with the ambiguities of an uncertain future. Also, it is time to adapt tasks, which requires an investment in the welfare of the ill child [3]. Anticipatory planning is requested for the child's end-oflife care, mainly if the service will be addressed at home, since the potential child and family's needs must be evaluated [4].

Terminally ill children require attentiveness and the affection that children need is often not provided in the hospital [3]. Once the hospital promotes anxiety, it would be the last place to put the dying child for comfort and extended care [3]. In the hospital, children become lonely and frustrated, which is less likely to occur at home. Palliative care providers are uniquely suited to facilitate end-of-life care for children outside of the hospital setting, which may enhance the child's quality of life until the end [5].

When the children are at home, they receive a variety of both psychological and social benefits because they are in a family environment. The family provides love and affection, as relatives share responsibilities for the care and love of a dying child. At home, the child can eat foods that he is used to and can pursue normal activities as much as possible [3]. Also, being at home can avoid confusion and unhappiness since the attention and discipline that the children are accustomed to is the same [3].

Terminally ill children react more strongly about changes such as fighting between the parents, changes in school, moving or separation, when they are in their environment than in hospitals [3]. In a more relaxed atmosphere, palliative care service and home care settings make terminally ill children more at ease and self-assured. Palliative care helps the children confront death more naturally and enables them to spend more productively the time they have left [3]. However, some parents are reluctant about palliative care service since it would mean the beginning of the end for their child. Frequently, it is not very easy for the parents to accept that the curative treatment does not work more for the child and it is time to start palliative care [3]. When the burden of illness increases and the quality of life reduces, it should direct the focus of care to the patient's individual needs following the dimensions of palliative care: physical, social, psychological, and spiritual [4].

Palliative home-care programs, with trained staff to meet the psychological and emotional needs of children of all ages, would appear to be the ideal answer to children's terminal care [3]. Home care for the dying child with cancer avoids much of the emotional stress, especially when the child is old enough to express an opinion. The children of grade-school age are the most affected emotionally children because they do not believe that a hospital is for their own well-being [3]. On the other hand, when the child is too reliant on the family, mainly younger children, it is necessary to keep a semblance of normality, and whenever possible, terminal care should take place in the home. However, the data regarding the frequency of children with cancer enroll in palliative care service nationally is uncertain [5].

Home care for the terminally ill child also results in psychological benefits for the family [3]. Parental satisfaction with care seems to be higher when a terminally ill child can die at home [5]. Parents adapted more quickly to normal social functioning after the death and experienced significantly less guilt over time than parents who did not choose home death for their child [5]. Also, caring for a child at home allows the family a better choice and more control over their environment. The family experiences more privacy and time together, as well as they clearly define roles in the care of the ill child. The comfort of being at home supports the child emotionally and reduces disruption to family life, particularly for siblings and parents [4].

\section{Children and family needs}

The levels of children's development, between the ages of birth and eighteen years, diversify much more drastically than adults' levels. Children are less in control of their own situation since the control increases with age. Also, children are, to varying degrees, dependent on a parent or other adult figure once the degree of dependence decreasing with age. One must keep in mind that growth, change and development are the very essence of childhood. Childhood is much more complicated than adulthood, although the dis- 
tinctions pointed out above between child and adult are simplistic indeed. The differences play a significant role in determining the different relationships a child and an adult will have with impending death, as well as the various methods of care needed to deal with each one [3].

Children's needs at the end of life must be considered, which imperatively includes the family and their needs [4]. For most children, they demand and require much more individual attention. Children's and their families' needs differ from those of adults in several aspects, and a comprehensive program like a palliative care could help fulfill those specific needs. A palliative care's customary practice regarding the patient and the family as a single unit of care would be especially beneficial in caring for the dying child [3].

Depending on the child's age and maturity, it is not expected that the child takes part in the decision-making process of their own care [3]. Although the consequences will affect the child, usually the family takes the responsibility of discussing and evaluating the end of life care of their child. Parents should talk about themes such as goals of treatment that may mitigate unnecessary suffering, ensure the care coordination, and facilitate the child's comfort. It is necessary to balance the quality and duration of life, as well as to decide on discontinuation or pursuing life-sustaining therapies. Finally, they also must discuss resuscitation and the location of death based on the child's and family's preferences [4].

However, if the child is an adolescent and has more maturity, additional aspects become essential in the decision-making process of their own care. Parents must consider what are the adolescent's preferences, clarify and integrate them into the care plan. Their preferences and needs may include knowing what to expect, understanding treatment choices, and choosing a natural death [3]. Adolescents also may prefer to stay in their own home over the dying process and to connect with their loved ones, which give them a sense of belonging. In this case, adolescents must choose people who should be alongside them during their last days [4].

During terminal illness and especially after the child's death, the family needs emotional and psychological advice. It is essential to include the family in the care provided, considering the deep anxiety experienced by the child and the family [3]. The dying child often awakens one of the parents' deepest fears - death before fulfillment. The experience of a child's terminal illness probably causes more psychological problems in families whose members are aware of the situation without being able to share it with the young child, than in families that the child has more maturity to understand [3].

Finally, an effective care program requires not only staff trained to deal with children on the medical, psychological and emotional levels, but also with the family. Physicians should be consciously aware of the conventional modes of adjustment used by parents to recognize the diverse forms of "coping behavior" that parents often manifest through denial [3]. Also, the professionals should be able to give the parents emotional and psychological guidance because the parents may wish to stay with the child day and night, or they may be reluctant to acknowledge how the child is feeling. The medical staff should demonstrate their willingness to answer all the parent's questions and clearly to discuss the child's disease, as well as to explain the various possible courses the illness could take. Only in this way, health care professionals will be able to anticipate their needs, problems, and sources of anxiety [3].

\section{Methods}

This study is a secondary research based on data from American federal agencies as the Centers for Disease Control and Prevention (CDC) and nonprofit organizations as the National Hospice and Palliative Care Organization (NHPCO). The quantitative survey of data on the place of death of children with cancer and the availability of palliative care services in the United States takes place through the agencies' websites cited, between January and February 2020. The descriptive statistical was used to analyze the data.

\section{Discussion}

Children with life-limiting illnesses are approximately 500,000 in the United States each year [1,2]. Researches show that palliative care services support only $1 \%$ of children who die in the country $[2,6]$. It is believed that most of the children are receiving palliative care services through adult palliative care centers that have little to no experience with the provision of pediatric care [2]. This defective system places highly vulnerable children and families at risk of receiving services from clinicians and nurses with inadequate expertise for the provision of pediatric palliative and hospice care [2].

In 2016, according to the National Vital Statistics Report - NVSR [7], 9,1\% of all the children ( 0 to 19 years old) died in the United States from malignant neoplasms. The cases of death as a result of 
cancer (Figure 1) was almost 18\% for children between 5 - 9 years old, and 14,3\% for children between 10 - 15 years old. Besides, cancer is the second more common cause of death for children age between 5 to 9 years old [7].

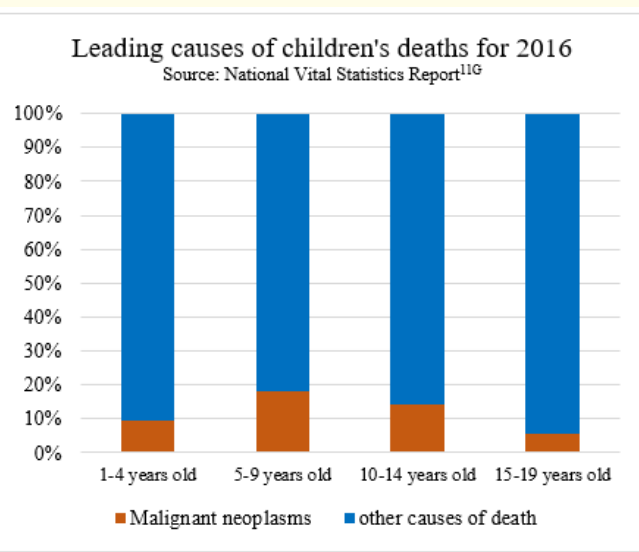

Figure 1: Leading causes of children's deaths for 2016 [7].

Children dying from cancer are comparable to adults dying from cancer, with a high quality of life before diagnosis, variable patterns during treatment and a rather fast decline during the end of life stage [4]. However, the needs of terminally ill children and their families are different from and more varied than those of adults. Different types of terminal illnesses and psychosocial development distinguishes end-of-life care for children and young adults from those for adults. Caring for children and young people is often considered by the palliative care industry as a skilled care service $[2,3,8]$.

Dying at home have been flagged as an indicator of the excellent quality of palliative care, which impact positively on the quality of life remaining, and parental adaptation after a child's death [5]. More children die of cancer than any other disease, and most of them prefer dying at home [4,5]. Like terminal ill adults, children desire to die at home, and it is essential to guarantee that they achieve this dream.

In 2007 , around $72 \%$ of children's deaths as a result of cancer occurred in the hospital, between inpatient and outpatient hospital sites, $11 \%$ of the children die at home, and $0.4 \%$ die in nursing homes [9]. In 2016, there is an increase in the number of deaths at home for children with cancer. According to the Centers for Disease Control and Prevention - CDC [10], the Multiple Cause of Death sur- vey of the 2016 year in the United States reveals that 2118 children aged less than 19 years died as a result of cancer. In this sense, it is possible to verify in figure 2 of these 2118 children, $37 \%$ died at home.

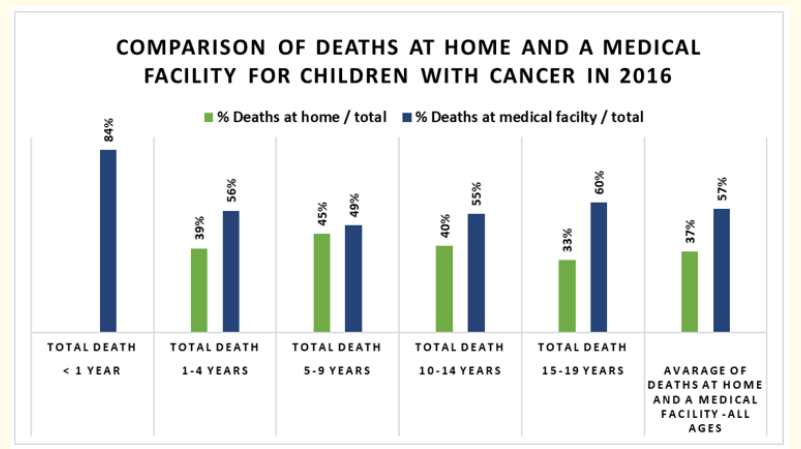

Figure 2: Comparison of death at home and a medical facility for children with cancer in 2016, according to CDC $[3,10]$.

However, it is not possible to affirm that all the children with cancer, who died at home in 2016 in the United States, was supported by a palliative care service. The frequency of children with cancer enroll in palliative care nationally, and parental satisfaction with palliative care are unknown [5].

Most researches about the frequency of children enroll in palliative care services; there is no data about the disease the children are facing. In 2007, children and young adults represented only $0.67 \%$ of total admissions in palliative care organizations [8]. In 2013 and 2014, according to National Hospice and Palliative Care Organization - NHPCO [6], of the total of palliative care admissions, less than $1 \%$ was pediatric and young adult population (less than 24 years old). Young adults between 15 to 19 years old are the most common age group in the palliative care admission and children between 1 to 4 years old are the least common. Palliative care centers that admit school-aged children have the highest median length of stay, and those that accept infants have the lowest range of stay. Generally, large palliative care centers more often accept children and young adults than medium or small organizations [8].

The support and availability of a palliative care service with an active pediatric program improve the outcomes of children with cancer at the end of life [4] and the availability of palliative care is an aspect that may influence the child's location of death [5]. Potential difficulties in providing palliative care for children are be- 
cause there are very few palliative cares in the United States with a pediatric program registered and specialized professionals. However, it is difficult to confirm how many palliative care services with the active pediatric program there are in the United States because most researches of this field are not confirmed or uncertain about this data.

A national survey conducted in 2007 by the National Hospice and Palliative Care Organization - NHPCO [11], showed that 78\% of responding palliative care services declared serving pediatric patients. Only $36.6 \%$ palliative care centers, who had responded to the survey, had a formal pediatric program in place, and $21.7 \%$ have specialized staff providing only pediatric services [11]. However, according to the National Summary of Hospice Care, another national survey in 2013 showed that only 14\% of participating palliative care programs have official pediatric palliative care services with specialized staff [2]. It is noteworthy that it is not possible to identify the number of palliative care services that participated in these two surveys mentioned above, and there is not the information of the sample used. Thus, the exact amount of palliative care services in the United States that have active pediatric programs is still uncertain.

If it is difficult for federal agencies or large nonprofit organizations in the United States to identify the number of palliative care services that have an active pediatric program, it will be much harder for families seeking such services for their terminally ill children. In this regard, we have collected information available to the general public on the availability of active pediatric programs from palliative care services on the NHPCO [12] website from January $20-29,2020$. The finding was that of the 2330 palliative care services available on the NHPCO [12] website, across the United States, only 81 palliative care services stated that they have an active pediatric program, which means only $3.48 \%$ of the total. The distribution in the US territory of palliative care services that claim to have an active pediatric program is shown in figure 3 .

This research does not mean that there is no active pediatric program in palliative care services in the states not listed in the figure, nor does it even mean that there are no more palliative care services with an active pediatric program in the states listed. However, this research demonstrates the number of palliative care services that clearly state and report on the NHPCO [12] website that they have an active pediatric program. It is noteworthy that the availability and accessibility of information are essential for the family seeking this service.

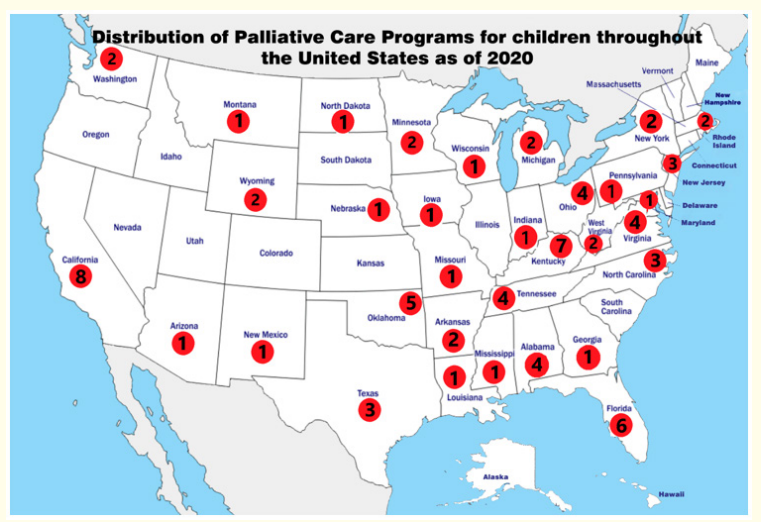

Figure 3: Distribution of palliative care services for children through United States [12].

One strength of this study is the use of available information for the general public, who need the palliative care services for their dying children, as a way to fulfill the lack of information in academic studies. Another strength is the use of the data from national agencies to confirm past studies and to fulfill the lack of information on academic studies in this field.

One limitation of this study was to work with studies in the field of palliative care services for children that have contradictory data, which makes it difficult to delimit a context for actions. Another limitation was the difficulties in finding data about palliative care for children, especially for those with cancer. Therefore, it was not possible to conclude the number of children with cancer supported by palliative care services.

However, the lack of data about the frequency of children with cancer who are being supported by palliative care services in the United States is one area where further work is needed. Also, studies about pediatric palliative care programs and parental satisfaction with palliative care services are more directions for future researches.

This study adds to the field once we explore more data about the availability throughout the United States of palliative care services for children. This new data can help to develop new actions to improve and increase the offer of palliative care services for children. Moreover, this study reveals that a higher number of children with cancer are achieving the dream to dye at home. On the other hand, there is no information available if palliative care services are supporting these children at home. 


\section{Conclusion and Recommendations}

The findings show that $37 \%$ of children with cancer are dying at home, and it is our opinion that this percentage should be increased. Whenever it is possible for children, they should die at home with the family present. We must increase the availability of children to die at home rather than in a medical facility. However, our findings indicate that only $3.48 \%$ of palliative care services in the United States declare the existence of an active pediatric palliative care program. This finding shows that the number of palliative care services for children is severely lacking in our country. Our recommendation is to increase this number.

There is some evidence that palliative care services that take care of the adult population are delivering services to children. Therefore, another recommendation would be those palliative care services that focus on the adults could consider offer training for their staff to address the specific needs of children and their families who are facing a terminal illness. The training must address the medical, nursing, psychological, or social needs that children and their parents demand. Also, the training must include all the palliative care staff, such as physicians, nurses, clergy, volunteers, and social workers. Henceforth, we must increase the specific knowledge of clinicians to address the needs of dying children and their families and make appropriate referrals to hospice in a timely fashion.

Finally, agencies in the United States Public Health Service, like as the National Institutes of Health (NIH) and Administration for Children and Families (ACF), could focus more attention on the needs for dying child and encourage further research by offering grants or contracts to develop more pediatric programs and services for children who are facing a terminal illness.

\section{Declaration of Interest}

The authors declare no conflict of interest.

\section{Bibliography}

1. Himelstein BP., et al. "Pediatric Palliative Care". The New England Journal of Medicine 350.17 (2004): 1752-1762.

2. Kaye EC., et al. "Provision of palliative and hospice care to children in the community: A population study of hospice nurses". Journal of Pain and Symptom Management 57.2 (2019).

3. Buckingham RW. "The handbook of hospice care". Prometheus Books (1996).
4. Bergstraesser E and Flury M. "Care at the end of life for children with cancer". In J Wolfe, BL Jones, U Kreicbergs and M Jankovic (Eds.), Palliative care in pediatric oncology: A reader (2018): 217-214.

5. Thienprayoon R., et al. "Hospice care for children with cancer: Where do these children die? Journal of Pediatric Hematology Oncology 37.5 (2015).

6. National Hospice and Palliative Care Organization. - 1. NHPCO's facts and figures: Hospice care in America (2015).

7. National Vital Statistics Report. Deaths: Leading causes of deaths for 2016, 67(6). M. Heron (Edition.), Division of Vital Statistics (2018).

8. Lindley L., et al. "Providing hospice care to children and young adults: A descriptive study of end-of-life organizations". Journal of Hospice and Palliative Nursing 11.6 (2009): 315-323.

9. Hendricks-Ferguson V. "Physical symptoms of children receiving pediatric hospice care at home during the last week of life". Oncology Nursing Forum 35.6 (2008): 108-115.

10. Centers for Disease Control and Prevention - CDC, National Center for Health Statistics. Multiple Cause of Death 19992017 on CDC WONDER Online Database. Data are from the Multiple Cause of Death Files, 1999-2017, as compiled from data provided by the 57 vital statistics jurisdictions through the Vital Statistics Cooperative Program (2020).

11. National Hospice and Palliative Care Organization. - 2. NHPCO's facts and figures: Pediatric Palliative and Hospice Care in America (2015).

12. National Hospice and Palliative Care Organization - NHPCO. Find a Care Provider, Filter Provider Type: Hospices (2020).

\section{Assets from publication with us}

- Prompt Acknowledgement after receiving the article

- Thorough Double blinded peer review

- Rapid Publication

- Issue of Publication Certificate

- High visibility of your Published work

Website: www.actascientific.com/

Submit Article: www.actascientific.com/submission.php

Email us: editor@actascientific.com

Contact us: +919182824667 